\title{
The Potential Influence of Medial Sinus wall Exposure During Lateral Sinus Floor Elevation Procedure on the Blood Supply to the Grafted Material: A Cohort Study
}

\author{
Gil S. Sluzkey ${ }^{1 *}$, Perry Raz ${ }^{1 * \#}$, Ilan Beitlitum ${ }^{1 * *}$ and Haim Tal ${ }^{1,2 * *}$ \\ ${ }^{1}$ Department of Periodontology and Oral Implants, Tel Aviv University, Israel \\ ${ }^{2}$ The Gerald Niznick Chair of Implant Research, Tel Aviv University, Israel
}

Submission: January 28, 2021; Published: February 11, 2021

*Gil S. Sluzkey and Perry Raz Share Equal Contribution

**Ilan Beitlitum and Haim Tal Share Equal Contribution

\#Corresponding author: Perry Raz, Department of Periodontology and Oral Implants, the Goldschleger School of Dental Medicine, Sackler Faculty of Medicine, Tel Aviv University, Tel Aviv, Israel

Abstract

Introduction: Different anatomical parameters may influence the success of lateral sinus floor elevation (LSFE), vascularization of the grafted sinus being a key factor for successful bone remodeling. Since the blood supply from the sinus floor and lateral wall may be compromised other sources such as the medial wall are of utmost importance.

Objective: This retrospective cohort study analyzed radiographically the influences of the surgical technique and sinus anatomy on the amount of medial wall exposure during LSFE.

Materials and methods: CBCT scans from 51 LSFE procedures were included. Measurements of the sinus mediolateral width augmented mediolateral width, augmented apico-coronal height from the top of the alveolar bone crest and from the sinus floor, the angle between the medial and the most lateral and medial drops of the filled bone substitute.

Results: The mean sinus maximal width was $18.18 \pm 2.81 \mathrm{~mm}$, and the mean augmentation filling height was $13.89 \pm 2.23 \mathrm{~mm}$. The mean medial and lateral filling drops were $4.51 \pm 2.11 \mathrm{~mm}$ and $2.06 \pm 1.35 \mathrm{~mm}$, respectively, representing $42 \%$ and $19.2 \%$ of the maximum filling height. The average sinus angle was $51.99 \pm 13.38^{\circ}$. A significant positive correlation was found between the medial drop and the sinus width $(\mathrm{P}<0.05)$.

Conclusion: After intended exposure of the medial wall during LSFE procedure, a significant medial and lateral drop in the level of the grafted bone substitute may be expected, thus reducing blood supply to the grafted material; This finding is more accentuated in wide sinuses. Therefore, selective compression of the graft material against the medial wall is advised during this procedure.

Keywords: Maxillary sinus; Sinus floor bone augmentation; Lateral sinus floor elevation; Cone beam CT; Blood supply to graft; Maxillary sinus graft vascularization

\section{Introduction}

Edentulous posterior maxillary ridges tend to present with alveolar bone disuse atrophy as well as sinus pneumatization; the second is characterized by osteoclastic activity below the sinus membrane [1-2]. To enable implant placement and restoration of the posterior maxilla, lateral sinus floor elevation (LSFE) with bone augmentation is commonly used. The surgical approach is derived from anatomical factors, especially the sinus width and the residual alveolar ridge volume. Systematic reviews have claimed implant survival rates greater than $90 \%$ following LSFE [3-5]. Lateral maxillary sinus wall antrostomy was first described by Tatum [6] and later modified by Boyne and James [7]. This procedure is challenging, requiring careful presurgical planning. Cones beam computed tomography (СВCT) is recommended as part of the presurgical evaluation [8-9]. The maxillary sinus is 
commonly described as a pyramidal cavity. Its anatomical borders are the maxillary tuberosity as a posterior wall and the zygomatic process of the maxilla in its apex. The nasal wall, which forms a bony septum separating the sinus from the nasal cavity, creates the medial wall of the sinus. The sinus floor is formed by the alveolar process of the maxilla. The roof of the maxillary sinus is bordered by the floor of the orbit [10-11].

Different anatomical parameters have been claimed to influence the success or complications associated with LSFE [1215]. These include the presence of tooth-root projections, the presence of underwood septae, [16] sinus floor convolution, and a thin or perforated Schneiderian membrane. Sharp angles between the lateral and medial walls increase the risk of membrane perforations [15]. Vascularization of the grafted filler is considered a key factor for successful bone growth, remodeling, and stability $[17,18]$. The blood supply of the grafted material is mainly provided by the posterior lateral nasal artery on the medial wall and the posterior superior alveolar artery and infraorbital artery on the lateral wall. In the lateral window approach, the blood supply from the lateral wall may be jeopardized, thus increasing the importance of a blood supply from the medial wall [19]. Moreover, it is important to emphasize the importance of exposing the medial wall to the grafted material by denuding it from the Schneiderian membrane. Previous studies have shown a greater reduction in the grafted vertical bone height in wide mediolateral sinuses during the healing period following LSFE [20]. To the best of our knowledge, the efficacy of surgically exposing the medial wall of the sinus to the sub-Schneiderian space and maintaining it during the healing stage of LSFE has not previously been studied. The aim of this retrospective cohort study was to radiographically analyze the possible influence of sinus anatomy on the amount of medial wall exposure to the graft material.

\section{Materials and Methods}

Fifty-one CT scans from 44 patients who were operated for sinus floor augmentation using the lateral approach were available. These were taken on the same CT set-up, 8 months postoperatively and before implant placement.

\section{Inclusion and Exclusion Criteria}

\section{Inclusion criteria}

a. Need for a dental implant in the posterior maxilla and less than $5 \mathrm{~mm}$ of vertical pristine bone, requiring a lateral approach.

b. No pathological findings or a thickened Schneiderian membrane.

c. CBCT 8 months post LSFE

d. Minimum age of 18 years

\section{Exclusion criteria}

a. Smokers

b. Recent (previous six months) radiotherapy of the head and neck region or recent treatment with bisphosphonates

c. Residual dentition with active periodontal disease

d. Poor oral hygiene or lack of compliance

e. Uncontrolled diabetes

f. Presence of a perforation of the Schneiderian membrane during, immediately or 8 months post-augmentation (seen on a CT scan).

\section{Surgical Procedure and Materials}

Patients were treated by two experienced periodontists (H.T, G.S) from the department of Periodontology and Oral Implants of the Tel Aviv University. Surgical procedures were performed under local anesthesia. Mid crestal and vertical buccal releasing incisions were preformed, and the lateral sinus wall was exposed by elevating a full thickness flap [21]. An antrostomy of the lateral sinus wall was made using a rotary instrument, and the bony window was removed using delicate curettes exposing the Schneiderian membrane. The membrane was separated from the sinus floor and peripheral to the window and was reflected from the lateral window and floor upwards and towards the medial wall of the sinus. A special effort was made to expose the medial bony wall to the same level of the buccal one, i.e., to the upper border of the window using a gauze soaked with lidocaine and epinephrine for better visualization. All sinuses were filled with xenograft bone substitute (DBX) (Bio-Oss ${ }^{\circledR}$, Geistlich Biomaterials, Wolhuse, Switzerland) using a disposable syringe.

An effort was made to ensure complete filling of the medial compartment of the sinus and then advancing peripherally and buccally. Graft material was gently compressed directly against the denuded surface of the medial bone. Periosteal elevator was used to support and tent the roof made by the Schnedirein membrane to avoid collapsing over the filled material. Finally, the window was covered with a resorbable collagen membrane Bio-Gide ${ }^{\circledR}$ (Geistlich Biomaterials, Baden-Baden, Germany) and the flap was approximated using resorbable sutures (Vicryl 4/0). Postoperative care included antibiotic administration (Augmentin $875 \mathrm{mg} /$ bid, GlaxoSmithKline, London, UK) for 1 week. Patients received analgesics and $0.2 \%$ chlorhexidine mouthwash for $1 \mathrm{~min}$, twice a day for 2 weeks. After 10-14 days, sutures were removed. Patients were examined after 1 and 2 weeks, and then every 1-2 months.

CBCT panoramic view and cross-sectional cuts were used for measurements using AB Dentpax Viewer software. From each $\mathrm{CBCT}$, a single cross section cut presenting the maximum bone 


\section{Global Journal of Otolaryngology}

fill height was selected, according to panoramic view (Figure 1); this section and the two neighboring ones were used for the measurements. The extent of medial wall exposure was evaluated by measuring the drop of the filling material as related to the maximal bone fill level and was defined as medial drop. The same measurement was taken to the bone filling height in the lateral wall and was defined as lateral drop.

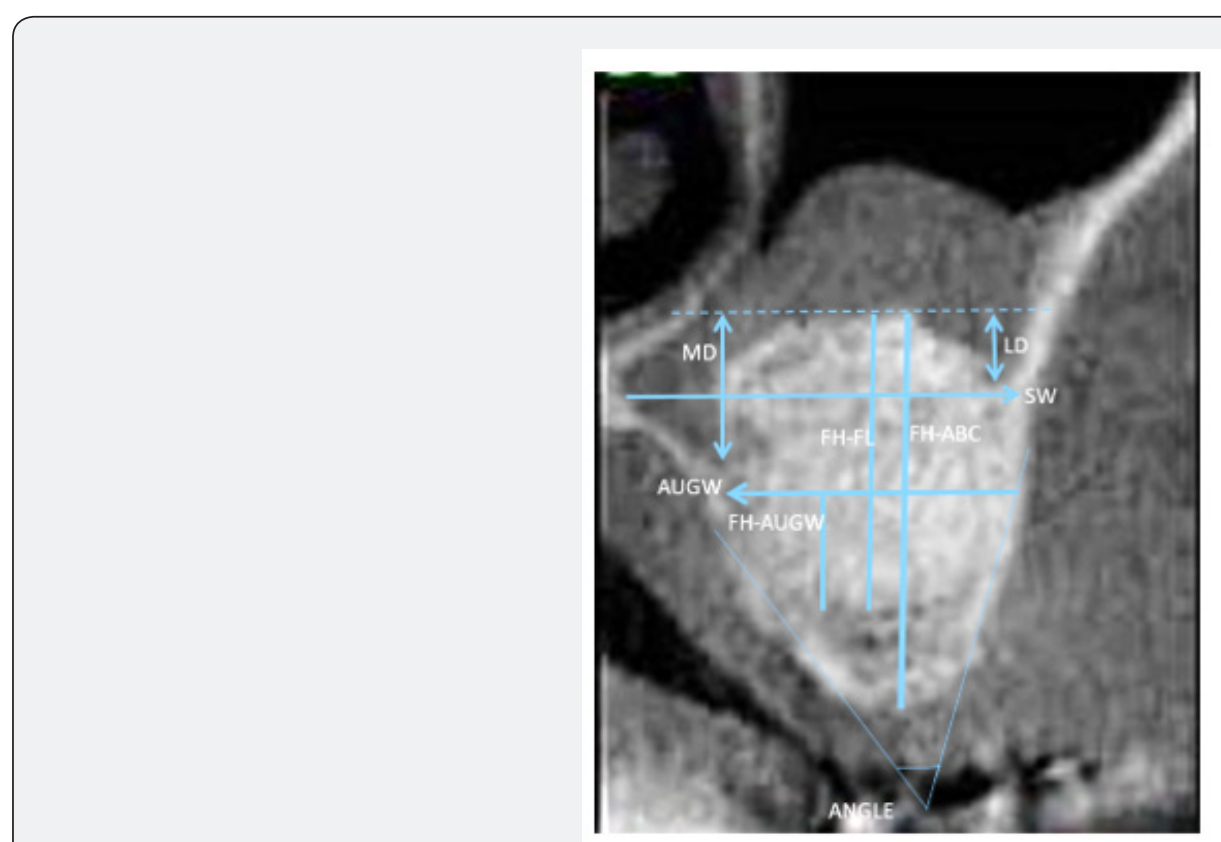

Figure 1: Representative cross-section picture of the sinus fill results analysis and measured parameters.

Abbreviation: SW: Sinus Maximal Width- Measured from the Lateral Wall to the Medial Wall at the Widest Level; AUGW: Maximum Augmentation Width - Measured at the Widest Level of the Augmented Bone; FH-ABC: Augmentation Fill Height -Measured from the Alveolar Bone Crest; FH-FL: Augmentation fill Height- Measured from the Sinus Floor at the Point of the Top of the Augmented Bone; FHAUGW: Augmentation fill Height Measured from the Maximum Augmentation Width Line; MD: Medial Drop- Measured from the Top of the Augmented Bone to the Lowest Point Near the Medial Wall where the Augmented Bone is in contact; LD: Lateral Drop- Measured from top of The Augmented Bone to the Lowest Point Near the Lateral Wall where the Augmented Bone is in Contact; ANG: Bucco-Palatal Sinus Wall Angle- the Angle between the Continued Line of the Buccal and Palatal Wall.

Parameters evaluated were: Maximum sinus width, maximum augmentation width, bone height from the alveolar bone crest to the top of the augmented material and, augmentation fill height from the sinus floor to the same top level. Augmentation fill height was also measured at the maximum augmentation width section, the Bucco- palatal sinus wall angle (as measured at the intersection between continuance lines of these walls), the medial drop and the lateral drop. All measurements are graphically presented in figure 1 and are described in table1.

Table 1: Description of the study population/cases.

\begin{tabular}{|c|c|}
\hline Number of patients & 44 \\
\hline Number of sinuses & 51 \\
\hline Gender & 21 females, 23 males \\
\hline Sinus fill material & Xenograft (DBBM)* \\
\hline Bilateral sinus fill & 14 sinuses \\
\hline
\end{tabular}

\section{Statistical Analysis}

Descriptive analysis was performed and correlations between the different parameters were tested using the Pearson correlation. Differences at a $p$ value $<0.05$ were accepted as being significant using the SPSS ver.20. A correction by Binyamini and Hochberg for multiple correlations tests was applied. ANOVA was used to examine the effect of the anatomical parameters regarding the filling results.

\section{Results}

The study population included 44 patients and 51 sinuses, since 7 of the patients had bilateral sinus augmentation (Table 1). All cases were successfully treated, without any significant complications. The radiographic measurements of the sinus anatomic and augmentation parameters provided the following data: the mean maximum width was $18.18 \pm 2.81 \mathrm{~mm}$ (12.31-26.75 $\mathrm{mm}$ ). The mean augmentation fill height from the sinus floor was $10.72 \pm 2.05 \mathrm{~mm}$ (5.31-15.59 mm). The mean medial filling drop was $4.51 \pm 2.11 \mathrm{~mm}$, and the lateral drop was $2.06 \pm 1.35 \mathrm{~mm}$. The mean sinus angle was $51.99 \pm 13.38$ degrees (Table 2). Significant positive correlations were found between the sinus maximal width and medial drop, sinus maximal width and lateral drop and between the medial drop and lateral drop. In addition, positive statistically significant correlations were found between the augmentation fill height measured from the sinus floor and the 


\section{Global Journal of Otolaryngology}

lateral drop. A significant negative correlation was found between the augmentation fill height measured from the alveolar bone crest and the sinus angle ( $\mathrm{p}<0.05,2$-tailed). These correlations were still significant after Binyamini-Hochberg correction for multiple correlations $(\mathrm{p}<0.05)$. All the other correlations examined are shown in Table 3. A significantly higher medial drop (42.91\%) than the lateral drop (18.76\%) percentage was found, as calculated in relation to the augmentation fill height measured from the sinus floor. A paired sample T-test was applied $(\mathrm{p}<0.05)$ (Figure 2).

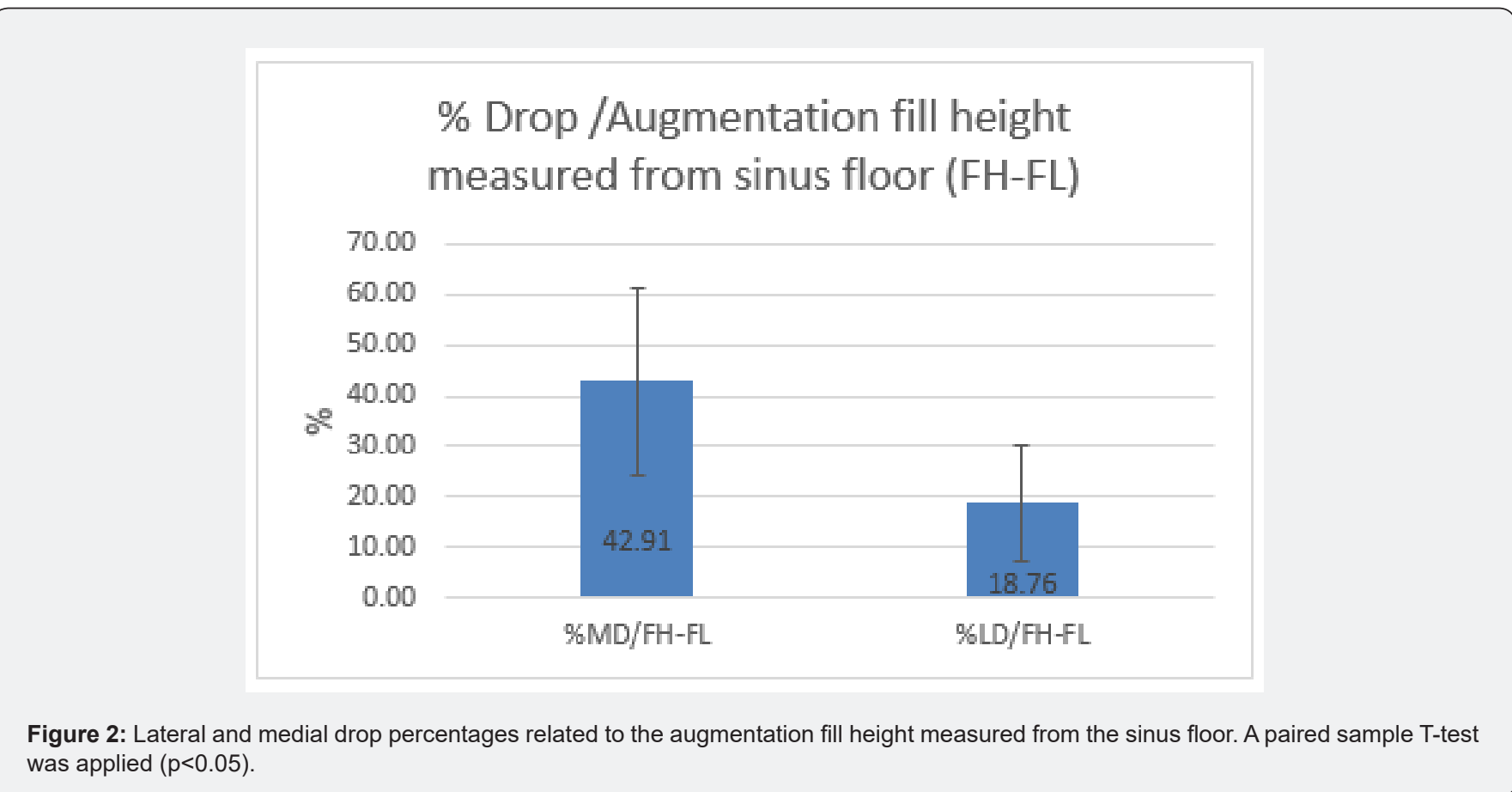

Table 2: Descriptive analysis of the anatomical and filling results $(N=51)$.

\begin{tabular}{|c|c|c|c|c|}
\hline Abbreviation & Measured parameter (mm) & Minimum & Maximum & Mean \pm Std. Deviation \\
\hline SW & Sinus maximal width & 12.31 & 26.75 & $18.18 \pm 2.81$ \\
\hline AUGW & Maximum augmentation width & 9.54 & 18.85 & $13.64 \pm 1.99$ \\
\hline $\mathrm{FH}-\mathrm{ABC}$ & $\begin{array}{c}\text { Augmentation fill height measured from the alveolar } \\
\text { bone crest }\end{array}$ & 9.96 & 20.34 & $13.89 \pm 2.23$ \\
\hline FH-FL & Augmentation fill height measured from the sinus floor & 5.31 & 15.59 & $10.72 \pm 2.05$ \\
\hline FH-AUGW & $\begin{array}{l}\text { Augmentation fill height measured from the maximum } \\
\text { augmentation width }\end{array}$ & 2.06 & 8.74 & $5.26 \pm 1.62$ \\
\hline MD & medial drop & 0 & 9.62 & $4.51 \pm 2.11$ \\
\hline LD & lateral drop & 0 & 5.34 & $2.06 \pm 1.35$ \\
\hline \multirow[t]{2}{*}{ ANG } & Bucco- palatal sinus wall angle & 26.87 & 99.97 & $51.99 \pm 13.38$ \\
\hline & Residual alveolar bone crest* (calculated) & & & $3.17 \pm 1.60$ \\
\hline
\end{tabular}

Table 3: Correlations between the measured parameters.

\begin{tabular}{|c|c|c|c|}
\hline Measured Parameter (mm) & $\begin{array}{l}\text { Pearson Cor- } \\
\text { relation }\end{array}$ & $\begin{array}{c}\text { Pearson } \\
\text { Correlation (p } \\
\text { value) }\end{array}$ & $\begin{array}{l}\text { After BH Correc- } \\
\text { tion (p value) }\end{array}$ \\
\hline Sinus maximal width - maximum augmentation width & $0.497 * *$ & 0.0002 & 0.0002 \\
\hline Sinus maximal width -medial drop & $0.342^{*}$ & 0.014 & 0.049 \\
\hline Sinus maximal width -lateral drop & $0.371^{* *}$ & 0.007 & 0.04 \\
\hline $\begin{array}{c}\text { Augmentation fill height measured from the alveolar bone crest - Augmentation fill height } \\
\text { measured from the sinus floor }\end{array}$ & $0.721^{* *}$ & 0 & 0 \\
\hline
\end{tabular}




\begin{tabular}{|c|c|c|c|}
\hline Augmentation fill height measured from the alveolar bone crest - the sinus angle & $-0.347^{*}$ & 0.013 & 0.049 \\
\hline Augmentation fill height measured from the sinus floor - maximum augmentation width & $0.653^{* *}$ & 0 & 0 \\
\hline Augmentation fill height measured from the sinus floor - the lateral drop & $0.429^{* *}$ & 0.002 & 0.011 \\
\hline Medial drop- lateral drop & $0.350^{*}$ & 0.012 & 0.049 \\
\hline $\begin{array}{c}\text { Residual crest height- Augmentation fill height measured from the maximum augmenta- } \\
\text { tion width line }\end{array}$ & $-0.466^{* *}$ & 0.004 & 0.004 \\
\hline Residual crest height-sinus angle & $-0.453^{* *}$ & 0.004 & 0.004 \\
\hline
\end{tabular}

*Significant ( $p<0.05,2$-tailed), ${ }^{* *}$ significant $(p<0.01,2$-tailed) $(\mathrm{N}=51)$ and correlation after Binyamini-Hochberg correction $(p<0.05)$.

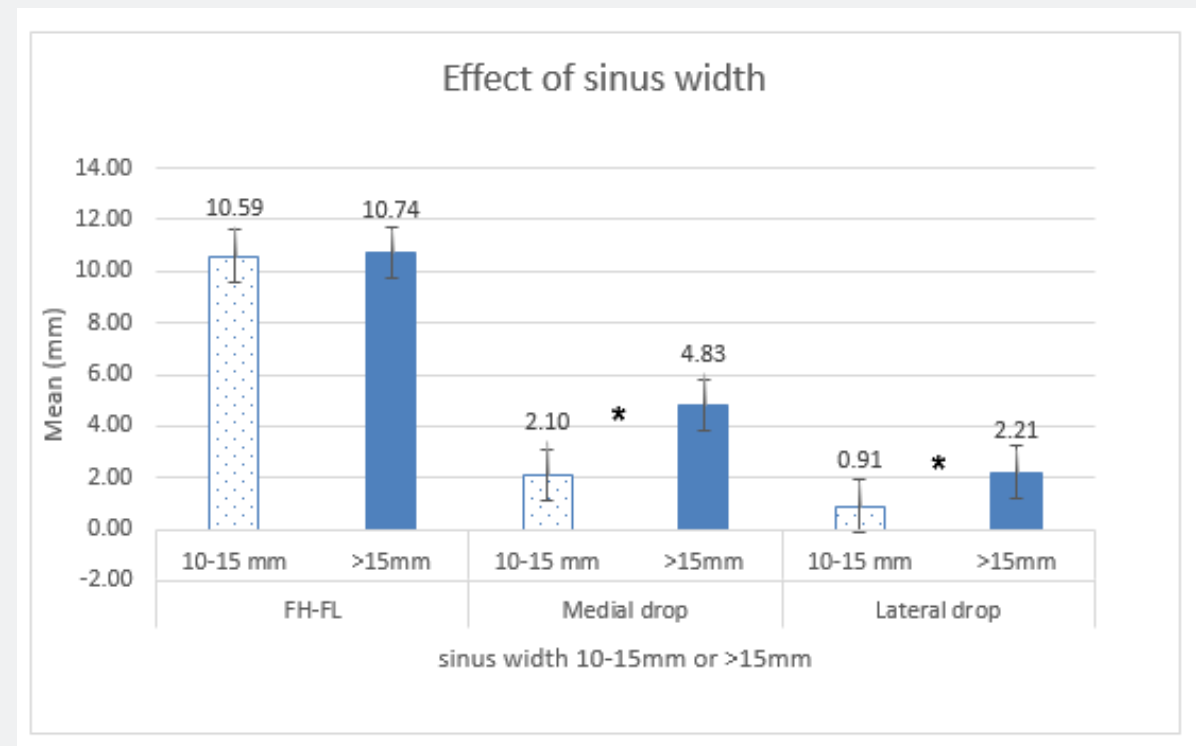

Figure 3: The effect of the sinus width on augmentation fill height measured from the sinus floor, medial and lateral fill drop. One-way ANOVA $(p<0.05)$.

Figure 4: The effect of the sinus angle on the mean lateral and medial drops. One-way ANOVA $(p<0.05)$. 
The sinus width was stratified into two groups: a group of sinus widths between $10-15 \mathrm{~mm}(\mathrm{~N}=6)$ and a group of sinuses wider than $15 \mathrm{~mm}(\mathrm{~N}=45)$. The effect of the sinus width on the lateral drop, mesial drop, and sinus fill (FH-FL) was examined, and ANOVA was applied. It was found that there was a significant drop and medial and lateral drops in sinuses wider than $15 \mathrm{~mm}$ in comparison to sinuses with a width between $10-15 \mathrm{~mm}$. The sinus width had no effect on sinus height fill as measured from the sinus floor (Figure 3). The sinuses were further stratified into three groups according to the sinus angle: sinus angle below $30^{\circ}(\mathrm{N}=2)$, sinus angle between $31-60^{\circ}(\mathrm{N}=35)$ and sinuses with an angle greater than $61^{\circ}(\mathrm{N}=14)$. The lateral drop was not affected by the sinus angle, while the medial drop was higher when the sinus angle was wider, but this did not reach statistical significance (Figure 4).

\section{Discussion}

This study evaluated the influence of specific anatomical factors of the sinus on the ability to maintain grafted bone levels of the sinus medial wall post LSFE. Our main results revealed that there was a significant medial drop that accounted for $42 \%$ of the augmentation height and that sinuses wider than $15 \mathrm{~mm}$ had statistically significantly higher medial and lateral drops than narrower sinuses. Zeng et al. found a positive correlation between wide sinuses and high (linear height) bone graft resorption, and their explanation was related to the vascular supply [22]. From an anatomical point of view, if denuded from soft tissue, the main blood supply to the grafted material may be from the medial bony wall, which is nourished by the posterior lateral nasal artery. Other sources of vascular supply are the posterior alveolar artery and the infraorbital artery on the lateral wall [19]. Zeng and his colleagues assumed that in wide sinuses, the blood supply is inadequate, resulting in higher bone resorption in comparison to narrow sinuses, where the intimate blood supply from the close walls enhances angiogenesis and graft remodeling [22].

From a biomechanical point of view, medial collapse may be related to a lack of bony support of the graft by the walls during the very early stage of healing, which may influence the level of the blood clots and the grafted material. In wide sinuses, this reduced support may result in reduced stability and a drop in the grafted material, like that observed against the medial wall and lateral wall. The sinus width, i.e., the distance between the medial and lateral walls, was negatively associated with the percentage of new bone formation using the lateral approach technique [2224]. In addition, in wide sinuses, it may be technically difficult to approach and reflect the Schneiderian membrane from the medial wall. In narrow sinuses, access to the medial wall may be easier.

Based on CBCT scan measurements of the palate-nasal recess located between the roof of the hard palate and the lateral wall of the nasal cavity, it was suggested that the location and angulation of such a recess would determine the degree of difficulty in elevating the membrane on the medial wall [25]. It is logical to assume that shortly after the surgical procedure, the cells of the membrane that are detached from the bony walls start to proliferate as part of a wound healing process; in this case, the membrane tends to penetrate and seal every gap next to it until it is "blocked" by connective tissue or bony attachment to the bony walls. This may establish the final level of the graft to the sinus wall level [26].

On the other hand, there are claims that variations in the Bucco palatal maxillary sinus width does not permit a meaningful sinus classification since there is a large variation in sinus width depending on the height level within the maxillary sinus and on the tooth position, and this does not permit a simple meaningful classification of narrow/average/wide sinuses. Nevertheless, a narrow maxillary sinus (i.e., $15 \mathrm{~mm}$ wide) is rather prevalent in the molar region; furthermore, a wider and shorter residual alveolar ridge is associated with a wider sinus width. This information could be considered during the choice of augmentation material and/or healing time during maxillary sinus fill in the various regions; it appears reasonable to suggest that a shorter healing time and/or the use of bone substitutes may be considered in premolar sites, while a longer healing time and/or the use of autogenous bone in combination with bone substitutes appear preferable in molar sites [24].

Avila et al. histologically examined the effect of sinus width on bone vitality and found a negative correlation between the two. Furthermore, these authors claimed that the remaining alveolar bone height did not appear to have any influence on the maturation and consolidation of an allograft in the maxillary sinus [25]. The sinus is a secluded space, where the graft material is in close contact with its bony floor and walls, which provides excellent healing potential. Therefore, almost any type of grafting material could be used successfully. When choosing a bone substitute graft for sinus fill, we should prefer a material that tends to absorb liquid and to expand and has an intimate contact with the bony walls, rather than a grafted material with a tendency to shrink.

The grafted material serves primarily as a space maintainer, which prevents the collapse of the elevated sinus membrane, and through its osteoconductive properties allows osteogenic cells from the surrounding bony walls to migrate into the interspace of the graft and generate new vital bone. This stresses the importance of exposing the medial sinus wall in LSFA $[7,26]$. In addition, graft remodeling occurs by osteogenic cells originating from the sinus bony envelope. Therefore, a wide reflection of the sinus membrane and medial wall exposure will provide a rich blood supply for the remodeling process, graft maturation and rapid vital bone formation. The wider the sinus is, the higher the amount of augmented material needed, along with a longer replacement time. In these cases, exposing the medial wall is essential, and the usage of osteoinductive grafts is highly recommended [21]. 


\section{Conclusion}

Presurgical evaluation of the sinus anatomy and the expected bone sinus augmentation volume post-surgery is beneficial for successful LSFE. Careful surgical planning and graft material selection are essential for minimizing filling drops. Post-surgery CBCT is also important for evaluating the filling drop and implant size selection. Significant exposure of the medial wall followed by selective compression of the graft material against it supports sinus floor augmentation procedures. This is especially important in wide sinuses (more than $15 \mathrm{~mm}$ ). Further study is recommended to evaluate the long-term results of medial drops after implant installation.

\section{Acknowledgment}

This study was supported by the Dr. Gerald A Niznick Chair of Implant Research.

\section{References}

1. Raghoebar GM, Onclin P, Boven GC, Vissink A, Meijer HJA (2019) Longterm effectiveness of maxillary sinus floor augmentation: A systematic review and meta-analysis. J Clin Periodontol Suppl 21: 307-318.

2. Chiapasco M, Zaniboni M (2009) Methods to treat the edentulous posterior maxilla:implants with sinus grafting. J Oral Maxillofac Surg 67(4): 867-871.

3. Wallace SS, Froum SJ (2003) Effect of maxillary sinus augmentation on the survival of endosseous dental implants. A systematic review. Ann Periodontol 8(1): 328-343.

4. Misch CE (1987) Maxillary sinus augmentation for endosteal implants: organized alternative treatment plans. Int J Oral Implantol 4(2): 49-58.

5. Tatum H Jr (1986) Maxillary and sinus implant reconstructions. Dent Clin North Am 30(2): 207-229.

6. Boyne PJ, James RA (1980) Grafting of the maxillary sinus floor with autogenous marrow and bone. J Oral Surg 38(8): 613-616.

7. Kawakami S, Botticelli D, Nakajima Y, Sakuma S, Baba S (2019) Anatomical analyses for maxillary sinus floor augmentation with a lateral approach: A cone beam computed tomography study. Ann Anat 226: 29-34.

8. Chan HL, Suarez F, Monje A, Benavides E, Wang HL (2014) Evaluation of maxillary sinus width on cone-beam computed tomography for sinus augmentation and new sinus classification based on sinus width. Clin Oral Implants Res 25(6): 647-652.

9. Bergh van den JPA, Bruggenkate ten CM, Disch FJM, Tuinzing DB (2000) Ana Anatomical aspects of sinus floor elevations. Clin Oral Impl Res 11: 256-265.

10. Whyte A, Boeddinghaus R (2019) The maxillary sinus: physiology, development and imaging anatomy. Dentomaxillofac Radiol 48(8): 20190205.
11. Testori T, Weinstein T, Taschieri S, Wallace SS (2019) Risk factors in lateral window sinus elevation surgery. Periodontol 2000. 81(1): 91123.

12. Testori T, Yu SH, Tavelli L, Wang HL (2020) Perforation Risk Assessment in Maxillary Sinus Augmentation with Lateral Wall Technique. Int J Periodontics Restorative Dent 40(3): 373-380.

13. Khehra A, Levin L (2020) Maxillary sinus augmentation procedures: a narrative clinical review. Quintessence Int 51(7): 578-584.

14. Tarnow DP (2001) Influence of anatomy on Schneiderian membrane perforations during sinus elevation surgery: three-dimensional analysis. Pract Proced Aesthet Dent 13(2): 160-163.

15. Rancitelli D, Borgonovo AE, Cicciù M, Re D, Rizza F, et al. (2015) Maxillary Sinus Septa and Anatomic Correlation with the Schneiderian Membrane. J Craniofac Surg 26(4): 1394-1398.

16. Rosano G, Taschieri S, Gaudy JF, Weinstein T, Del Fabbro M (2011) Maxillary sinus vascular anatomy and its relation to sinus lift surgery. Clin Oral Implants Res 22(7): 711-715.

17. Elian N, Wallace S, Cho SC, Jalbout ZN, Froum S (2005) Distribution of the maxillary artery as it relates to sinus floor augmentation. Int J Oral Maxillofac Implants 20(5): 784-787.

18. Traxler H, Windisch A, Geyerhofer U, Surd R, Solar P, et al. (1999) Arterial blood supply of the maxillary sinus. Clin Anat 12(6): 417-421.

19. Jang HY, Kim HC, Lee SC, Lee JY (2010) Choice of graft material in relation to maxillary sinus width in internal sinus floor augmentation. J Oral Maxillofac Surg 68(8): 1859-1868.

20. Kaufman E (2003) Maxillary sinus elevation surgery: an overview. J Esthet Restor Dent 15(5): 272-282.

21. Zheng X, Teng M, Zhou F, Ye J, Li G, Mo A (2016) Influence of Maxillary Sinus Width on Transcrestal Sinus Augmentation Outcomes: Radiographic Evaluation Based on Cone Beam CT. Clin Implant Dent Relat Res 18(2): 292-300.

22. Bertl K, Mick RB, Heimel P, Gahleitner A, Stavropoulos A, Ulm C (2018) Variation in bucco-palatal maxillary sinus width does not permit a meaningful sinus classification. Clin Oral Implants Res 29(12): 12201229.

23. Avila G, Wang HL, Galindo Moreno P, Misch CE, Bagramian RA, et al. (2010) The influence of the bucco-palatal distance on sinus augmentation outcomes. J Periodontol 81(7): 1041-1050.

24. Chan HL, Monje A, Suarez F, Benavides E, Wang HL (2013) Palatonasal recess on medial wall of the maxillary sinus and clinical implications for sinus augmentation via lateral window approach. J Periodontol 84(8): 1087-1093.

25. Danesh Sani SA, Engebretson SP, Janal MN (2017) Histomorphometric results ofdifferent grafting materials and effect of healing time on bone maturation after sinus floor augmentation: a systematic review and meta-analysis. J Periodontal Res 52(3): 301-312.

26. Wallace SS (2006) Maxillary sinus augmentation: evidence-based decision making with a biological surgical approach. Compend Contin Educ Dent 27(12): 662-668. 
(C) This work is licensed under Creative DOI: 10.19080/GJO.2021.24.556128

\section{Your next submission with Juniper Publishers will reach you the below assets}

- Quality Editorial service

- Swift Peer Review

- Reprints availability

- E-prints Service

- Manuscript Podcast for convenient understanding

- Global attainment for your research

- Manuscript accessibility in different formats

( Pdf, E-pub, Full Text, Audio)

- Unceasing customer service

Track the below URL for one-step submission https://juniperpublishers.com/online-submission.php 